\title{
Armonía y ritmo en la Poética de Aristóteles: una delimitación conceptual
}

\author{
Virginia Aspe Armella \\ Facultad de Filosofía y Ciencias Sociales \\ Universidad Panamericana \\ virginiaaspe@yahoo.com.mx
}

\section{Planteamiento del problema}

En este escrito me propongo establecer la delimitación conceptual que los términos armonía y ritmo exigen desde la Poética de Aristóteles. Para alcanzar mi objetivo, mostraré que en la Poética el ritmo y la armonía se entienden de manera distinta a como los entendió Platón y a como los entendía el propio Aristóteles en sus obras naturalistas. Dado que en la Poética se consideró que la armonía y el ritmo siempre acompañan a la mímesis, comenzaré por explicar qué entendía el estagirita por mímesis poética, ya que la delimitación conceptual de los términos armonía y ritmo suponen un mismo ámbito de significación. La Poética instaura un nuevo orden de la realidad distinto del mundo metafísico y del mundo corpóreo y natural. Esta primera premisa debe justificarse antes de entrar en tema, ya que si no se entiende el peculiar estatuto óntico que confiere Aristóteles al ente poético, difícilmente podremos comprender las nociones aquí planteadas. 
Comencemos por citar la definición de tragedia que aparece en la Poética, a saber: «la imitación de una acción esforzada y completa, de cierta amplitud, en lenguaje sazonado» (Aristóteles 2000; 24-28). He aquí el primer elemento a tener en cuenta para nuestra investigación. Aristóteles ubica al ritmo como un medio de imitación (Aristóteles, Poética 1, 1447b 21) y afirma que «el ritmo es un aderezo del lenguaje de la tragedia» (Aristóteles, Poética 6, 1449b 29), ubicándolo en el nivel del lógos mientras que define al lenguaje sazonado como «aquél que tiene ritmo, armonía y canto» (Aristóteles, Poética 6, 1449b 28-29). Para Aristóteles, el ritmo y la armonía se insertan en los versos y en los cantos (Aristóteles, Poética 6, 1449b 27-30), ya que «la elocución poética incluye muchas alteraciones del lenguaje» (Aristóteles, Poética 2, 1448a 1-8), al considerar que «tales alteraciones, en efecto, las permitimos los poetas» (Aristóteles, Poética 25, 1460b 12-13).

Es aquí donde entra el elemento ficticio que Aristóteles tiene en cuenta en la Poética. Aunque Aristóteles no utiliza el término «ficción» con la carga moderna y subjetiva, otorga una carga no natural e irreductible al ámbito predicamental en el quehacer del poeta, cuando valida que éste realice alteraciones (Aristóteles, Poética 21, 1458a 1-8; 60b 12-13). Uno de los argumentos es que «todos disfrutan de las obras de imitación, lo prueba el hecho de que hay seres cuyo aspecto real nos molesta (por ejemplo, animales repugnantes y cadáveres) pero nos gusta su imagen representada». Otro es que cabe placer no sólo por la imitación, sino por la mera ejecución, el color, o alguna otra causa semejante (Aristóteles, Poética 4, 1448b 12). 
2. El estatuto lingüístico de «armonía» y «ritmo» en la Poética y su delimitación conceptual frente al sentido metafísico de Platón y al naturalista del resto del corpus aristotélico

Comencemos, pues, a establecer las delimitaciones conceptuales planteadas en la primera parte de este escrito. En el capítulo cuarto de la Poética, Aristóteles introduce las nociones de ritmo y armonía:

[...] siéndonos pues naturales el imitar y la armonía y el ritmo (porque es claro que los metros son partes de los ritmos) y partiendo de tal principio innato, y sobre todo, desarrollándolo por sus naturales pasos, los hombres dieron a luz a la poesía partiendo de improvisaciones (Aristóteles, Poética 4, 1448b 24-28).

El pasaje ha sido traducido de múltiples maneras. Incluso, hay quienes sostienen que no hay dos sino tres causas naturales de la poesía: la mímesis, el placer natural por la imitación y la armonía y el ritmo que la acompañan; en todo caso y para efectos de esta investigación, es indudable que Aristóteles considera katá phýsin (principios innatos) i) a la mímesis, ii) a la armonía y al ritmo y iii) a la tendencia al placer que siempre acompaña a las imitaciones.

El filósofo alude, ya sea de manera directa o no, a las nociones de armonía y ritmo en seis capítulos de la Poética, a saber, 1, 2, 3, 4, 9 y 25. Asimismo, en su obra nos remite indirectamente a una metodología intertextual de esos términos, por ejemplo la referencia a la Retórica ${ }^{1}$. Ya que el ritmo y

1 Alfonso Reyes ha sido quien mejor ha abordado la necesidad de una metodología intertextual en la Poética en sus comentarios a esta obra en La crítica literaria en la edad ateniense. Para este interesante tema sugiero confrontar mi artículo (Reyes 2005; 215-237). 
la armonía -con base en la Poética- acompañan siempre a la mímesis, considero que no podemos hacer una delimitación conceptual de los términos sin antes definir qué entendía Aristóteles por mímesis. El de Estagira consideraba mímesis a todo arte e imitaciones, a todas las especies poéticas (ver Aristóteles, Poética 1, 1447a 20) de las cuales, cada una se distinguió por imitar con medios diversos, objetos diversos, de manera diversa ${ }^{2}$. Para Aristóteles, todo arte poético imita con la voz; sin embargo, dependerá de diversos factores -si ésta se «da sola», con ritmo o con armonía-, para determinar de qué especie poética se trata. Afirma el filósofo en Perí Hermeneías lo siguiente: "porque la palabra es el lugar donde pueden aparecerse -sin hacer lo que son- las ideas de todas las cosas» (ver Aristóteles, De Int. IV, 17a 5). Con lo dicho, queda de manifiesto que la voz es el medio de imitación más propio del ser humano (ver Aristóteles, Cat. III, 1b 10-22). Si las artes poéticas tienen, pues, algo en común, es ser imitaciones mediante la voz; y si sus especies se diferencian con base en los acompañamientos de la voz por la armonía, el ritmo o ambos, observamos que estos dos últimos conceptos forman el lenguaje sazonado que es el medio para la representación de las acciones. Ahora bien, recordemos que el ritmo y la armonía siempre acompañan a la mímesis, por esto vemos que el concepto de lenguaje sazonado no es mero adorno extrínseco a la representación que el poeta añade o sobrepone, sino que más bien el lenguaje poético es rítmico, melódico o ambos, por el carácter de la mímesis poética. Es así que conviene comprender el tipo de mímesis de la Poética para penetrar en la significación del ritmo y la armonía que la acompañan.

2 Por ejemplo, se imita con la imagen y la figura o con la voz; se imitan acciones humanas y lo anterior puede hacerse de manera grandiosa o cómica. 
La carga metafísica de la imitación platónica es el distintivo específico que se opone al de la aristotélica. En el Timeo, al ser el Demiurgo un dios hacedor de formas (ver 39d, 48e, $50 \mathrm{c})^{3}$, se muestra que la clave en la comprensión de la realidad platónica estaba en la mímesis como representación de un modelo o paradigma supremo, único modelo que se bastaba a sí mismo. Semejante concepción de mímesis traía consigo una connotación jerárquica: la realidad estaba siempre en un mundo invisible que sustentaba las imágenes visibles de la realidad natural. Este mimetismo del primer modelo o paradigma hizo que las realidades artísticas tuviesen una triple degradación ontológica: al ser imitaciones de la realidad natural, devenían en una copia de la copia del mundo verdaderamente real. Bien se sabe que ésta fue la causa por la que Platón expulsó a los poetas de la pólis (ver Platón, Rep. X, 19 c-d y Leyes, 713e).

Para Platón, si todo es mímesis del modelo ideal ${ }^{4}$, hay una carga ontológica del término en tanto que los objetos representados sólo tienen sentido porque remiten al otro. Sin embargo, en Aristóteles la mímesis no remite a algo previo o derivado de realidad óntica alguna ${ }^{5}$. Se ha señalado reiteradamente que Aristóteles lleva el mundo platónico de las sustancias separadas al seno de la realidad natural, pero poco se ha dicho respecto a que la separación entre el discípulo y el maestro tuvo como punto de partida a la Poética. En ésta, Aristóteles redefine el concepto platónico de mímesis al otorgarle estatuto de ficción poética en el sentido en que he explicitado el término ficción. No quiero con esto separar exce-

3 También ver el texto de (Sorabji, 1983).

4 Por ejemplo, también lo dice en Critias, 107d.

5 En mi opinión quien mejor ha visto actualmente este sentido aristotélico de mímesis es (Halliwell, 1998; 117) por ejemplo. 
sivamente la filosofía aristotélica de la de su maestro. Pese a que al ubicar el mundo de las ideas en la realidad natural, y a que Aristóteles se aparta del concepto metafísico de mímesis, existe en el corpus cierta comprensión del término como algo que remite a otro; es decir, como un referente de la representación ya no ideal platónica pero sí naturalista.

Este concepto mimético naturalista del arte da cuenta de la frase el arte imita la naturaleza, ya que en el corpus la ousía aparece como la realidad primera. Pero en la Poética, la clave está en que la sentencia el arte imita a la naturaleza no presupone jerarquización entre uno y otro mundo. Como veremos más adelante, lo que imita el arte de la naturaleza no es su ser, acto o ousía, sino la función de las cosas y su estructura. Lo poético versa sobre un mundo caracterizado precisamente por ser intelectual y no natural. Entre la redefinición que el estagirita hace del concepto de mímesis, está precisamente su ubicación en lo específico del ser humano, la razón, más que en la vertiente metafísica de la realidad. Es indudable que en Aristóteles el fundamento de la mímesis es gnoseológico y no metafísico, por lo que la Poética parte de este ámbito para desarrollar sus especies desde la verosimilitud y la ficción.

Notemos la evolución que se ha dado paulatinamente del concepto naturalista hacia el poético de la mímesis aristotélica. En De anima, III 8, se sostiene que el alma es cierta armonía al explicar el conocimiento entre el intelecto y la cosa. Ahí se propone la metáfora del sello y la cera para ejemplificar la similitud o correspondencia entre lo conocido, la operación que conoce y la facultad que lo hace y se da aun la fuerza de la operación cognoscitiva al remitente o punto de partida del mimetismo, la realidad natural. En cambio, en la Poética, pese a hablar de la imitación de la realidad, se valida la separación con lo natural cuando se dice que «nada impi- 
de que algunos sucesos sean tales o se ajusten a lo verosímil o a lo posible, que es el sentido en que los trata el poeta» (Arist., Poética 1, 451b 30-32). Pero no es el propósito del escrito ahondar en el mimetismo gnoseológico del De anima indudablemente fysikós, sino en aquello que opera el poeta mediante la voz y la palabra, mimetismo que da lugar a un género literario específico: la tragedia como arte poética. En ella «se imitan acciones esforzadas de hombres en acción, en deleitoso lenguaje, que inspiran compasión y temor, y que dan lugar a la catarsis» (Arist. Poética 9, 1450a 20-31).

Si Aristóteles ubica las ideas en la realidad natural, es decir, si sitúa la mímesis en la esfera de la naturaleza y no en la de lo ideal, no por ello pasa el naturalismo mimético a la Poética sino que, gracias a los medios de la elocución, del canto y de la melopeya, opera un nuevo orden y sentido de mímesis, ajeno al de la realidad natural. En la Poética, la armonía y el ritmo se conciben como i) algo connatural, ii) algo que siempre acompaña a la mímesis poética, iii) algo que tiene que ver específicamente con el lenguaje, y iv) algo cuyo estatuto produce placer.

Aparece así la hipótesis de la investigación: el concepto poético de mímesis en Aristóteles se distingue explícitamente del de mímesis en sus obras naturalistas. Si ésto es así, los conceptos aristotélicos de armonía y ritmo -que de acuerdo con la Poética acompañan siempre a la mímesis- tendrán un significado diverso al de la tradición platónica que se deriva del Timeo y al del naturalismo del resto de las obras del Corpus. Las razones por las que aquí suponemos que la Poética permite esta aproximación, se expondrán a continuación.

En primer lugar, esclarezcamos los conceptos de ritmo y armonía según los comprendieron los contemporáneos de Aristóteles y Platón, para contar con elementos de aproxima- 
ción a ellos en la Poética. En general, los filólogos de la época están de acuerdo al decir que la armonía designaba finura, juntura, encaje, cierre, acuerdo, tratado, ley, orden, justa proporción, acorde musical..., y que el ritmo significaba alternancia de fenómenos opuestos en el mismo proceso, movimiento regular recurrente, alteridad dentro de algo común ${ }^{6}$.

Notemos cómo cada uno de estos significados puede enfatizarse según se entienda la palabra mímesis. Si, como en Platón, imitar es una tarea metafísica, la juntura, el acuerdo, la ley u orden indicarán prioritariamente participación. El significado remitirá, pues, siempre a un primer analogado. Respecto del ritmo, digamos también que puede cambiarse un significado por otro, según si se enfatiza que la alternancia de fenómenos opuestos gradualmente se predica en razón de un primer analogado, o si no hay subordinación alguna a otro. Lo mismo ocurriría si dijésemos que los movimientos regulares o simétricos se dicen en orden a uno primero que mueve. La clave de comprensión siempre estaría dada por un movimiento rítmico inicial o por un moviente primero en el primer caso; en el segundo, no se remite a causa eficiente inicial alguna.

En el caso de Aristóteles, cabe decir que no hay reconocimiento de otro más allá de la representación misma de la acción (que remotamente tiene su origen en la naturaleza al imitarse acciones, pero como veremos, la sola imitación de acciones del individuo no es aún lo que especifica al arte poético). En él, la armonía poética no remite a la armonía natural sino que, como hemos visto por el acompañamiento del ritmo y la armonía, remite a los aspectos melódicos del lenguaje. Ritmo y armonía en la Poética son medios para la

6 Sigo el rastreo filológico del especialista Someville (1975; 43-54). 
imitación, connaturales al hombre y aderezos del lenguaje de la tragedia. Ciertamente, Aristóteles busca en la Poética una generación análoga a la natural, pero distingue la metabolé o generación natural del ser vivo, del concepto artístico que genera la imitación de acciones humanas.

Esta especie de generación se conoce como poietiké, ya que nace la poética cuando el arte de la palabra encuentra su propia estabilidad y perfección a la manera de un ser vivo. Se trata de la búsqueda consciente de la representación de acciones humanas a la manera de los seres vivos en la que no media modelo alguno en acto y en la que los medios son especies lingüísticas distintas de las que remiten a datos exteriores. Aristóteles claramente dice que las acciones en la tragedia pueden ser representadas como son, o como al poeta le hubiera gustado que fuesen o que hubieran sido, posible o necesariamente. En ningún momento Aristóteles involucra la vertiente ontológica o acto de realidad alguna, sea metafísica o natural. Lo que hay en su tratado son posibilidades y verosimilitudes que no establecen jerarquía con un modelo primigenio. Prueba de lo anterior es el sostener que, en la tragedia, resulta mejor el imposible que convence que el posible que no lo hace. Así pues, y con el carácter de indudable, la Poética tiene como criterio último la idea de ficción y no la de realidad. Ya Platón desde República III, 398d, había sostenido que el canto constaba de tres elementos $\lambda$ ó $\gamma o v \tau \varepsilon$

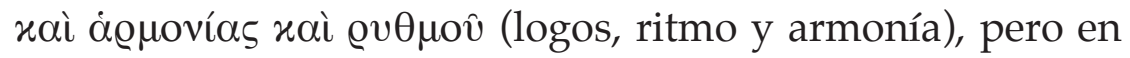
la Poética este mismo proceso cognitivo ocurre sin mediación óntica ni natural.

Con base en lo anterior, adentrémonos en el verdadero sentido de la mímesis y de la armonía y ritmo en Poética IV (1448b 4-28): las causas naturales de la poesía son las reproducciones imitativas y el placer que producen las imitaciones 
(algo que tenemos en común con los animales), y éstas van siempre acompañadas de dos elementos naturales, la armonía y el ritmo. Por eso, todo arte ha de ser imitativo, pero mientras que algunas artes sólo imitan con ritmo como la danza, y otras con armonía como la música, hay algunas que imitan mediante la voz, sea que incluyan al ritmo, la armonía o ambos. Nada queda de natural en la tragedia más que el impulso inicial de hacerla. La poética surgió de las capacidades naturales de algunos hombres hasta que ella misma encontró su estado perfecto. Al llegar a dicho estado, la poética cobró su propia autonomía a la manera de un organismo vivo.

Empero, ella y sus especies pertenecen a un peculiar género existencial que se delimita conceptualmente como verosimilitud. Sumamente representativo de ésto es el argumento aristotélico que sugiere que lo poético rebasa el orden categorial y predicamental cuando dice que «se debe preferir lo imposible verosímil a lo posible creíble» (Poética 24, 1460a 26-27), y cuando dice que «es verosímil que también sucedan cosas al margen de lo verosímil» (Poética 24, 1461b 15), ésto cuando había dicho antes que nada impedía que el poeta tratase los sucesos ajustándose a lo verosímil o a lo posible (ver Poética 1, 451b 30-32). Al hacerse acompañar siempre la mímesis del ritmo y la armonía, cabe también decir que así como la capacidad natural mimética deviene por arte en una especie poética así también ocurre que el ritmo y la armonía en la Poética cobran estatuto distinto del natural cuando su formalidad está en la medida del lenguaje y en su estructuración auditiva y fonética. Es así que el tema de la armonía y el ritmo los había tratado Aristóteles en sus obras físicas, por ejemplo en Física I-2 194a 21 de un modo diverso, donde se les dio sentido cosmológico, en cambio, en la Poética considera los versos o metros poéticos como ritmos y las melodías 
musicales como armonías. Hemos citado antes el pasaje de De An., III-8 que dice que el alma es cierta armonía y existen otros pasajes que son claves en la evolución de los términos que nos ocupan, así que ahora interesa esclarecer qué son la armonía y el ritmo en la Poética.

3. La evolución de los términos armonía y ritmo en la Poética

En una primera lectura, el tratado toma la armonía y el ritmo como elementos naturales que acompañan la capacidad natural humana compartida con el resto de los animales: la mímesis. Ritmo y armonía aparecen siempre como conceptos paralelos a la actividad mimética. El punto de partida es, pues, un impulso. Ambos son considerados como hormé, pero más adelante y conforme avanza el desarrollo de la Poética-que en sus tres capítulos iniciales trataba un sentido estático de la mímesis para analizarla después en el cuarto en su dinamismo natural-, concluye que la tragedia encuentra su estado perfecto con un nuevo sentido de mímesis poética y, ahí mismo, Aristóteles comienza a concebir un sentido distinto de ritmo y armonía: el que es por arte poético.

Sostiene que los poetas se distinguen por el metro con el que componen -ahora el ritmo es metro- $y$, en la medida en que el capítulo 4 explica la gestación de la tragedia, reduce la importancia del ritmo natural. Con lo dicho, aparta al coro del papel protagónico que tenía y separa la tragedia de la danza al quitarle fuerza al concepto natural de ritmo. En cambio, dice que la poesía encuentra su metro adecuado en los yambos. Considera a Homero el primer poeta en lograr producir este arte, pues dice que en un sentido Homero es igual que Sófocles en cuanto imitador y también el primero en haber introducido las imitaciones dramáticas (ver Poética 
4, 1448b 30-32). Allí, Aristóteles le concede también el mérito de saber decir lo falso como verdadero (ver Poética 24, 1460a 18-19), tanto como quien entendió que la clave de lo poético estaba en «encubrir lo absurdo sazonándolo con los demás primores» ( Poética 24, 1460a 35; 1460 b2).

Aristóteles considera que la estabilidad de la tragedia se logró quitando el metro trocaico para estabilizarse en el yámbico, el más flexible de los metros (Poética 4, 1448b 5-1449a 30). Este género poético encuentra paulatinamente su plenitud en la medida en que se aproxima más a un lenguaje parecido al coloquial en el sentido que en el diálogo hay más metros yámbicos que en los hexámetros, que rara vez usamos (Poética 4, 1449a 25-28). En dicha evolución, Aristóteles sustituye el páthos que marca el ritmo del coro por la palabra. Lo anterior se opone claramente a la interpretación de Nietzsche, quien pone el origen de la tragedia en el coro cuando precisamente en el capítulo 4 de la Poética se sostiene que Esquilo comenzó a aumentar el número de actores y a disminuir la parte del coro.

Para Aristóteles, la tragedia llegó a su perfección cuando disminuyó el tetrámetro apto para la poesía satírica y la danza, y se dio importancia al diálogo. A diferencia de Nietzsche, para Aristóteles la tragedia pone la fuerza en el lenguaje y, por ello, insiste: «todo esto lo hace el poeta mediante el lenguaje». Sin embargo, en el capítulo 9 nos explica que «el poeta ha de ser un constructor de fábulas más que un creador de versos». La melodía y la dicción deben de ser parte del todo que es la representación de acciones, tal y como lo había asentado en Poética 6, cuando explica las partes de la tragedia: fábula, caracteres, dicción, pensamiento, espectáculo y armonía (1449b 35). En el citado pasaje señala, además, que la melodía es el más elevado de los adornos de la 
tragedia (1456a 20-35). Ahora bien, dadas las condiciones de su evolución, y habiendo dicho cuáles fueron sus elementos esenciales, cabe preguntarnos: ¿Cómo es que Aristóteles encontró que era posible ceder el paso de la mímesis natural a los hombres - un modo de conocimiento que por naturaleza tienen desde sus primeros conocimientos de la infanciahasta llegar a una mímesis artística cuyo estatuto está en la ficción? ¿Cómo puede explicar Aristóteles que la armonía y el ritmo -naturales al cuerpo humano- pudieron devenir en elementos artísticos plenamente lingüísticos y musicales?

4. La cuestión psicológica en la armonía y el ritmo poéticos

Autores como Charles H. Kahn (1979) han estudiado el tema de la percepción interior en los tratados naturalistas de Aristóteles tales como De Memoria y reminiscencia, De los sueños, De sensu, y De anima, para probar que lo que se plantea como un problema en los primeros tratados naturalistas que mencionamos, se resuelve como aporía en el De anima. Khan sostiene que la doctrina de la percepción en el estagirita habla no de un sentido común como después lo interpretó el medioevo, sino de una sensibilidad común -Koinía aesthetá-, de acuerdo con De An., II-6. Así, desde el texto De memoria et reminitentia se dice que el tiempo se percibe por una facultad común -próton aisthetikón-, tal y como después sostienen De Anima II 6 y III-1, 425b 4.

Como el tiempo es el número del movimiento, éste se relaciona directamente con el sensible común, pero el sentido del tiempo no es idéntico al sentido del movimiento (la prueba que da Aristóteles, y con él Khan, es que si así fuera sería común a todos los animales), así, distinguen que una cosa es el tiempo y otra es el movimiento. El tiempo es la medida 
del movimiento y en consecuencia el ritmo es la armonía del movimiento.

Podría considerarse que esta aclaración es innecesaria, sin embargo, el punto es clave respecto a la diferencia entre la mímesis de Platón y la de Aristóteles, pues bajo este supuesto mímesis se convierte en un principio que no está atado a la temporalidad y a su opuesto, la eternidad, aquello que en Platón daba estatuto primigenio al mundo de las ideas. En Aristóteles, en cambio, la clave está dada por el movimiento natural de los seres y sólo después cabe hablar de tiempo. De hecho, la idea de infinito cambia en ambos autores griegos.

Mientras que para Platón la infinitud está atada a la eternidad, para Aristóteles la idea de infinito viene por la materia. Estas dos vertientes ónticas hacen que se considere la idea de conocimiento y percepción de modo diverso. El aristotelismo propone una única facultad para todo el conocimiento humano y un único acto reflexivo en la diferenciación del contenido de la percepción. Ya no se trata de recordar o remitir a acto alguno primigenio, pues no hay escisión entre lo real natural y lo ideal, tampoco entre la inteligencia y lo sensible. La conclusión del argumento es que los objetos de los diferentes sentidos deben de hecho ser percibidos por alguna facultad única.

Esta facultad es concretamente una, indivisible, separada en su ser. La tesis propone que para Aristóteles, el alma es una función (Fortenbaugh 1979; 133-143), y que el placer es un movimiento del alma y un encuadre intenso y perceptible del estado natural (Aristóteles, Rh., 1369b 33-5). El placer es un tipo de movimiento, y a través de esto se logra conectar con los tipos de armonía musical (ver Política VIII-7, 1341b 32-1342a 27). Desde esta adecuada interpretación, la cuestión relevante reside en que la sensación es una actividad común 
al cuerpo y al alma, un movimiento del alma que es producido por el cuerpo, lo que quiere decir que en Aristóteles no existe el dualismo mente-cuerpo. Asimismo, la percepción es una información concerniente al mundo exterior, una capacidad humana de apropiación de lo sensible que no requiere de una solución puente o medial.

Si esto es así, la mímesis es percepción visual y vocal que puede serlo de objetos naturales tanto como de artísticos o ficticios. En este argumento cobra importancia la metáfora, la cumbre del lenguaje poético, pues la metáfora establece la percepción de similitudes no como copia de modelo alguno. Es por lo anterior que Aristóteles afirma que el hacedor de metáforas no hereda de nadie su oficio, ya que esto es noticia de genio más que de aprendizaje.

La terminología lingüística de la Poética arranca en el capítulo 19, sosteniendo que en el pensamiento se incluyen todos los efectos que deben ser producidos por medio del lenguaje, para en el capítulo 20 tomar ya formalmente la solución poética en 1457a, y culmina en el capítulo 25, donde reitera la tesis aquí propuesta cuando señala las críticas al lenguaje del poeta. El capítulo 21 explica que la palabra poética precisa primero de sustantivos y no de verbos para mostrar que el poeta no imita sucesos de otros sino que instaura nuevos seres. En el capítulo 22 descara la propuesta al mostrar cómo el ritmo es parte del léxico ofreciendo la clasificación de las palabras en la poesía.

Al contrastar las preguntas que abrieron este apartado, podríamos concluir que el ritmo y la armonía poéticos son el paso o evolución de una forma de lenguaje que representaba de manera jerarquizada a las cosas mediante usos trocados para ceder paso a una forma de lenguaje dialógica a través de yambos, capaz de establecer diálogos que representen 
acciones con lenguaje rítmico y musical. La paulatina evolución de este vuelco lingüístico se opera separando el protagonismo del coro -excesivamente atado al temperamento y afecciones de la representación-para que surja en cambio un lenguaje sazonado apto para la representación racional de acciones. Este vuelco lo produjo Esquilo, aunque quien echó a andar el proceso inicialmente fue Homero.

\section{Consideraciones finales}

Hay un desencadenamiento radical en los conceptos de armonía y ritmo en la Poética, en la medida en que queda establecido el estatuto lingüístico de la tragedia. Para nuestro autor, la armonía es verso en el lenguaje (no música instrumental), pues se vale de la elocución o expresión mediante las palabras y de la composición del canto o melopeya para instaurar un orden que rebasa el nivel categorial. Ésta es la delimitación conceptual que hemos de tener en los conceptos de ritmo y armonía de la Poética. Una dimensión lingüística sazonada que sigue criterios de verosimilitud y apariencias ajenas tanto al ámbito metafísico de Platón como al veritativo aristotélico, según lo enunciado en Analíticos posteriores.

Es así que en la Poética, el ritmo es un medio para la imitación entendiendo un sentido de ritmo del que son parte los metros y versos y donde el ritmo es un aderezo del lenguaje. Asimismo, la armonía es medio para la imitación en el sentido en que también es aderezo del lenguaje de la tragedia. El lenguaje sazonado o rítmico y armónico de la Poética consiste en el uso formal de metros yámbicos que paulatinamente se desarrollan hasta llegar a los hexámetros -los menos comunes-, y complicar así racionalmente el lenguaje quitándole protagonismo a las pasiones y afecciones cotidianas. Por eso 
la elocución poética incluye muchas alteraciones del lenguaje, ya que ésas las permite Aristóteles a los poetas.

En conclusión, el ritmo y la armonía de la Poética tienen estatuto lingüístico y no natural. El lenguaje al cual remiten está estructurado poéticamente -con verso, o con música, o con canto, o con ambos-, pero, en todo caso, a una estructuración artificial producida psicológica y racionalmente, ya no referida directamente a existente alguno ni a movimientos naturales del cosmos. Precisamente por esto, basta con que se lea en voz alta una tragedia para tener la representación o mímesis poética. 
Bibliografía

Aristóteles (2000). Poética. Juan David García Bacca (trad.). México: UNAM.

Fortenbaugh, W. (1979). Aristotle's rethoric on emotions. Jonatham Barnes, Malcolm Schofield \& Richard Sorabji (eds.). Articles on Aristotle: psychology and aesthetics. Londres: Duckworth.

Halliwell, S. (1998). Aristotle's Poetics. Chicago University Press.

Kahn, C. (1979). Sensation and counciousness in Aristotle. Jonathan Barnes, Malcolm Schofield \& Richard Sorabji (eds.). Articles on Aristotle: psychology and aesthetics. Londres: Duckworth.

Reyes, A. (2005). El concepto aristotélico de tragedia en el ensayo Las tres electras del teatro ateniense de Alfonso Reyes. Perennidad y apertura de Aristóteles: reflexiones poéticas y de incidencia mexicana. México: Publicaciones Cruz.

Someville, P. (1975). Essai sur la poétique d'Aristote et sur quelques aspects de sa posterité. París: Vrin.

Sorabji, R. (1979). Time, creation and continuum. Jonathan Barnes, Malcolm Schofield \& Richard Sorabji (eds.). Articles on Aristotle: psychology and aesthetics. Londres: Duckworth. 


\section{Resumen}

En este escrito me propongo establecer la delimitación conceptual que los términos armonía y ritmo exigen desde la Poética de Aristóteles. Para ello mostraré que en la Poética el ritmo y la armonía se entienden de manera distinta a como los entendió Platón y a como los entendía el propio Aristóteles en sus obras naturalistas. La Poética instaura un nuevo orden de la realidad distinto al del mundo metafísico y al del mundo corpóreo y natural. Para Platón hay una carga ontológica de la mímesis, en cambio, en Aristóteles, no remite a algo previo o derivado de realidad óntica alguna. En la Poética lo que imita el arte de la naturaleza no es su ser, sino la función de las cosas y su estructura. Lo poético versa sobre un mundo caracterizado por ser intelectual y no natural: en Aristóteles el fundamento de la mímesis es gnoseológico y no metafísico.

Palabras clave: armonía, ritmo, mímesis, Aristóteles.

\section{Abstract}

My purpose in this paper is to lay down the conceptual delimitation of the terms harmony and rhythm within Aristotle's Poetics. I will show that Aristotle's understanding of harmony and rhythm differs from that of Plato and from the stance he holds within his naturalistic works. In the Poetics Aristotle refers to a new order of reality, different from that of the metaphysical, the corporeal and the natural worlds. For Plato mimesis has an ontological meaning, whereas in the case of Aristotle, mimesis does not refer to anything previous or derived from any ontic reality. In the Poetics, art does not imitate the being of nature, but the function of things and their structure. The poetical realm is about a world characterized 
as intellectual, not as natural: for Aristotle the foundation of mimesis is epistemic, not metaphysical.

Key words: harmony, rhythm, mimesis, Aristotle. 